\title{
LEI DE INICIATIVA POPULAR 8.930/94 - A MODIFICAÇÃO NA LEI DE CRIMES HEDIONDOS: um estudo sobre o processo legislativo
}

\author{
POPULAR INITIATIVE LAW 8.930/94 - THE AMENDMENT OF THE HEINOUS \\ CRIMES LAW: a study of the legislative process
}

Arley Felipe Amanajás*

\begin{abstract}
Resumo
Os Mecanismos de Democracia Direta (MDD) foram pensados para possibilitar uma participação popular para além do voto. Esses instrumentos procuram mesclar, em uma democracia representativa, opções de participação direta da cidadania nas decisões estatais. O trabalho tem como objetivo analisar a aplicação das Leis de Iniciativa Popular no Brasil através de um olhar sobre o seu processo legislativo. Diferente de outros trabalhos sobre o tema, buscamos identificar em uma análise endógena ao Congresso Nacional, especialmente na Câmara dos Deputados, onde as leis de origem popular se iniciam, como ocorre o processo decisório e o estabelecimento de seu conteúdo, além de buscar compreender a influência do Poder Executivo neste contexto. Para isso, com base na bibliografia sobre o tema, explicitamos as discussões sobre a formação e o papel das coalizões na aprovação das matérias no legislativo e no estabelecimento da agenda governamental, além de destacar como se materializa a participação das instituições estruturantes do processo legislativo brasileiro (comissões, colégio de líderes e partidos políticos) no tocante à aprovação das iniciativas populares de leis. O trabalho tem por objeto a análise do primeiro caso de iniciativa popular legislativa aprovado no Brasil até o presente momento: a Lei 8.930/94 - Altera a lei de crimes hediondos. Percebe-se que foi nas Comissões e no Plenário da Câmara dos Deputados onde os projetos ganharam seus conteúdos finais. Os deputados fizeram algumas modificações nos projetos originais oriundos da participação popular, mas em nenhum caso chegaram a descaracterizar ou mudá-lo de forma substancial.
\end{abstract}

Palavras-chave: Iniciativa Popular de Leis; Mecanismos de Democracia Direta; Processo Legislativo.

\begin{abstract}
Direct Democracy Mechanisms (MDD) were designed to enable popular participation beyond voting. These instruments seek to merge, in representative democracy, options for direct participation of citizens in state decisions. This paper aims to analyze the operation of Popular Initiative legislation in Brazil through a look at its legislative process. Unlike other works on the subject, we seek to identify, by means of an endogenous analysis of the National Congress, especially in the Chamber of Deputies,

\footnotetext{
* Mestre em Ciência Política pela Universidade Federal do Pará (UFPA/Brasil). E-mail: arley.amanajas@gmail.com.
} 
where legislation of popular origin begins, how the decision-making process and the establishment of its content occurs, as well as seeking to understand the influence of the executive branch in this context. For this, based on the literature on the subject, we explain the discussions on the formation and role of coalitions in the approval of legislation and the establishment of the government agenda, while also highlighting how participation of the structuring institutions of the Brazilian legislative process materializes (commissions, college of leaders, and political parties) regarding the approval of popular law initiatives. The purpose of this paper is to analyze the first case of popular legislative initiative approved in Brazil to date: Law 8.930/94 - Amendment of the heinous crimes law. It is notable that it was in the Parliamentary Commissions and the floor of the Chamber of Deputies where projects acquired their final content. Deputies made some modifications to the original projects derived from popular participation, but in no case did they mischaracterize or substantially change it.

Keywords: Popular Initiative Legislation; Mechanisms of Direct Democracy; Legislative Process.

\section{Introdução}

Os mecanismos de participação popular nas tomadas de decisões e nas escolhas feitas pela administração do Estado sempre foram alvos de grandes debates entre os estudiosos que se dispuseram a discutir a democracia. Ora restringindo essa participação à delegação de poderes em um sistema representativo puro, dentro de um Estado burguês, ora partindo da participação ativa do povo como fonte necessária para se alcançar a verdadeira democracia, rompendo com a estrutura do Estado capitalista, vários pensadores, dos mais distintos âmbitos do espectro político, analisaram a inserção da vontade popular na construção do Estado.

Neste sentido, surgem nas democracias representativas alguns institutos característicos das democracias diretas, mesclando a forma puramente delegada de representação da vontade popular com mecanismos que possibilitam uma maior participação da população. É o caso do plebiscito, o referendo, a revogação popular de mandatos e a iniciativa popular de leis (IPL), entre outros. O presente trabalho tem como objetivo analisar, através de uma pesquisa qualitativa, o instituto da iniciativa popular de leis no Brasil.

Iniciaremos debatendo sobre os conceitos e especificidades dos Mecanismos de Democracia Direta (MDD) não só no Brasil, mas também como esses mecanismos são configurados nos países da América Latina. Em seguida, expomos a trajetória histórica 
destes institutos no Brasil e focamos a análise no modelo institucional brasileiro da iniciativa popular, e a crítica feita a ele por alguns autores que estudaram o tema.

Ao final do trabalho, apontamos que o modelo institucional brasileiro que rege a iniciativa popular de Leis, apesar da crítica feita pela literatura, não aponta uma grande discrepância ao ser comparado aos modelos dos países da América Latina. Em seguida, apresentamos o primeiro caso de uma lei de origem popular aprovada no Brasil: a Lei 8.930/94, que implicou em modificação na lei de crimes hediondos.

Analisando o caso específico sob o viés proposto, percebemos que o Poder Executivo detém uma grande influência e participa diretamente da aprovação deste projeto de lei. Neste sentido, para demonstrar isso, analisamos o processo legislativo utilizando como base os documentos digitalizados e os perfis biográficos dos Deputados extraídos do sistema de acompanhamento da tramitação dos PL no site da Câmara dos Deputados, que estão disponíveis publicamente.

\section{A trajetória histórica dos Mecanismos de Democracia Direta no Brasil}

Segundo Maria Victória Benevides (1991), falar em democracia semidireta no Brasil é "uma nova velha ideia". Durante muito tempo ela foi posta à margem pelos estudos clássicos da Ciência Política, e estudada em forma de "curiosidade histórica" pelos juristas e pelos estudos parlamentares.

A primeira aparição dos institutos da democracia semidireta no Brasil ocorreu bem antes de se falar em um estado democrático brasileiro, ou mesmo em República. O princípio da revogação de mandados eletivos (Recall) apareceu, ainda que embrionariamente, em 16 de fevereiro de 1822, instituído pelo Príncipe Regente. O instituto durou menos de um ano, porém foi a primeira tentativa de abrir uma possibilidade de intervenção direta do eleitor na representação parlamentar (BENEVIDES, 1991).

O recall aparece novamente na história legislativa brasileira com a República, nas constituições de alguns estados como São Paulo, Rio Grande do Sul, Santa Catarina e Goiás. A Constituição de São Paulo (1891) inovou de maneira radical, admitindo não só o Recall, mas também o Veto Popular - que consistia na anulação das deliberações das 
autoridades municipais mediante proposta de um terço e aprovação de dois terços dos eleitores (cerca de $20 \%$ da população do estado). Apesar da inovação (ou talvez até por conta dela), os dois institutos foram retirados do texto constitucional em 1905. Já nos estados do Rio Grande do Sul, Santa Catarina e Goiás, apesar da previsão do instituto ter durado mais tempo (no Rio Grande do Sul foi abolida em 1913), não existem dados sobre sua aplicação em nenhum destes estados (BENEVIDES, 1991).

Segundo Benevides (1991), a primeira previsão de plebiscito na história constitucional brasileira foi através da carta outorgada por Getúlio Vargas em 1937, que estabelecia quatro hipóteses de utilização do instrumento:

1) $\mathrm{O}$ artigo $5^{\circ}$ previa a possibilidade de o presidente levar a resolução do Parlamento que aceitava a subdivisão, desmembramento, anexação ou formação de novos estados, ao plebiscito das populações interessadas;

2) $\mathrm{O}$ artigo 63 previa a possibilidade de, a todo tempo, poderem ser conferidas ao Conselho da Economia Nacional, mediante plebiscito, poderes de legislação sobre algumas ou todas as matérias da sua competência, cabendo ao Presidente informar mediante decreto as respectivas condições e matérias;

3) A terceira possibilidade de plebiscito prevista na Carta de 1937 é a de que, caso haja conflito entre o Presidente da República e o Parlamento no tocante a aprovação de emendas à Constituição, caberia ao Presidente, dentro de trinta dias, enviar o projeto em conflito ao plebiscito nacional, sendo que o projeto só se incorporaria à Constituição caso lhe fosse favorável o plebiscito. Este constitui um típico caso de plebiscito facultativo vinculante;

4) A última previsão do instrumento na Carta de 1937 consistia na submissão da própria Constituição a plebiscito, na forma regulada em decreto pelo Presidente da República o que nunca ocorreu.

Benevides (1991) afirma que a redemocratização de 1945 não trouxe ampliação aos institutos da democracia semidireta, muito pelo contrário. Esses mecanismos permaneceram contaminados com a lembrança do ditador e da experiência francesa do cesarismo. Sendo assim, na nova regra constitucional, predominou o princípio de uma "representação pura", repudiando-se a ideia de mandato imperativo. 
Esse posicionamento é consubstanciado pela Lei Constitucional $n^{\circ} 9$ de 1945 . Esta lei previa, em seus "considerandos",

que a eleição de um Parlamento dotado de poderes especiais para, se o entender conveniente, votar a reforma da Constituição no curso de uma Legislatura supre com vantagem o plebiscito de que trata o art. 187 [da Constituição de 1937], e que, por outro lado, o voto plebiscitário implicitamente tolheria ao Parlamento a liberdade de dispor em matéria constitucional (BRASIL, 1945).

Interessante notar que, mesmo suprimindo alguns casos de possível aplicação do plebiscito, a mesma Lei Constitucional $n^{\circ} 9$ conservou em seu conteúdo (Art. 174), a possibilidade de haver um plebiscito quando os poderes Legislativo e Executivo não conseguissem entrar em acordo sobre algum tema de Emenda Constitucional - muito parecido com o que é previsto na Constituição chilena, atualmente.

A semelhança com a atual Constituição do Chile, no que se refere ao plebiscito, vai além. Os Mecanismos de Democracia Direta no Chile foram utilizados pela Ditadura Militar de Augusto Pinochet em, no mínimo, quatro oportunidades (1978, 1980, 1988 e 1989). Após a redemocratização do país, os legisladores constitucionais restringiram drasticamente a possibilidade de utilização desses mecanismos (ALTMAN, 2010; WELP, 2008).

Possivelmente, a ideia por trás da previsão do plebiscito para sanar disputas entre os poderes foi vista como uma forma de buscar alternativas para as inevitáveis crises e possíveis paralisias decisórias que os pesquisadores afirmavam ser inerentes ao sistema presidencialista. Com o apoio popular sobre a reforma, em caso de crise, a última palavra seria dada pelos cidadãos.

No Brasil, apesar de após 1945 serem discutidos alguns projetos sobre a implementação de plebiscitos e referendos na ordem constitucional, só com o plebiscito de 1963 o mecanismo tomou destaque novamente.

\footnotetext{
A realização do plebiscito de 1963 não encontraria respaldo jurídico, portanto, no texto constitucional vigente, uma vez que se tratava de matéria sobre sistema de governo. O plebiscito tornou-se possível após intensa batalha parlamentar, iniciada logo em seguida à renúncia do presidente Jânio Quadros e à edição da Emenda Constitucional $\mathrm{n}^{\mathrm{o}} 4$ de 1961, instituindo o parlamentarismo (BENEVIDES, 1991, p. 119).
}

Com a vitória do "não", o presidencialismo sagrou-se vitorioso com grande maioria dos votos. O caso do plebiscito de 1963 reflete uma "consulta plebiscitada", ou 
como chama Altman (2010), plebiscito consultivo, no qual o que se busca é uma aprovação à determinada medida ou proposta. Nesse caso, segundo Benevides (1991), a maioria dos votantes não compreendia a distinção entre as duas formas de governo, tendo ido votar a favor ou contra maiores poderes ao então presidente João Goulart.

Outro instrumento de participação presente no Brasil é a Iniciativa Popular Legislativa (IPL). Avritzer (2006) faz uma sinopse das iniciativas populares que, até a data de seu texto, foram aprovadas pelo Congresso. Os três projetos apresentados até então eram o Projeto de Combate à Corrupção Eleitoral, com um milhão de assinaturas, apresentado pela CNBB; o projeto que visava mudar a Lei de Crimes Hediondos, com 1,3 milhão de assinaturas; e o projeto sobre o Fundo Nacional de Habitação Popular, com mais de três milhões de assinaturas.

Segundo o autor, o primeiro se tornou lei através de uma rápida tramitação no Congresso. Os outros dois foram resultado de "processos mistos, envolvendo a iniciativa popular e ação de parlamentares". No caso do projeto modificativo da Lei de Crimes Hediondos, houve uma participação maciça de famílias de pessoas assassinadas de forma cruel, além da adesão da autora de telenovelas Glória Perez, que foi importante tanto para coleta de assinaturas como para a tramitação do projeto (AVRITZER, 2006).

Comparando os mecanismos de referendo, plebiscito e a iniciativa popular de leis no Brasil, Avritzer (2006) afirma que os dois primeiros - além de terem sido pouco utilizados - foram convocados para dirimir conflitos internos ao Poder Legislativo. Dentre os três casos abordados pelo autor de iniciativa popular de leis:

\footnotetext{
Pelo menos dois expressam fortes movimentos da sociedade civil, a CNBB e o Movimento Nacional de Luta pela Moradia. O terceiro movimento expressa uma personalidade pública capaz de dar visibilidade midiática ao movimento. No entanto, não há dúvidas de que dada a amplitude da legislação, os três mecanismos são pouco utilizados no nível nacional e ainda menos no estadual (AVRITZER, 2006, p. 41).
}

Em modo de conclusão, o autor aponta que as poucas experiências de iniciativa popular de leis foram prejudicadas por um procedimento pouco claro de tramitação no Congresso, já que o instituto não possui um trâmite legislativo prioritário, confundindoas com as demais normas de impulso ordinário (AVRITZER, 2006). 
Sonia Fleury (2006) defende que o termo "iniciativa popular" designa, de modo geral, diferentes maneiras de participação popular no efetivo exercício dos poderes Legislativo e Executivo. No termo, inclui o plebiscito e referendo (quando iniciados através de manifestação da população), conselhos gestores, orçamento participativo, conselhos e, quando usado em termos estritos, significa a iniciativa popular legislativa.

Fleury (2006) relembra que, além do plebiscito, do referendo e da inciativa popular, foi incluído no primeiro turno de votação da atual Constituição o instituto do veto popular, que consiste, na prática, como um referendo revocatório, utilizado para a derrogação de leis, já aprovadas no Congresso, por parte da população. O veto popular não foi aprovado em segundo turno de votação.

A autora ainda lembra que em 2004 a OAB, com o apoio da CNBB e o MST lançaram a Campanha Nacional em Defesa da República e da Democracia, na qual os senadores Pedro Simon (PMDB-RS) e Eduardo Suplicy (PT-SP) lideraram propostas de emendas à Constituição no sentindo de instituir a revogação de mandatos (Recall) para o Executivo e para as Casas Legislativas (FLEURY, 2006).

Ainda como parte da referida Campanha, houve a proposição do jurista Fábio Konder Comparato, transformada no Projeto de Lei 4.718 de 2004, que pretendia "resgatar o princípio constitucional da soberania popular", ao permitir que plebiscitos e referendos fossem convocados, tanto por iniciativa popular, com $1 \%$ do eleitorado, seja por iniciativa de um terço dos membros de uma Casa do Congresso (FLEURY, 2006).

\section{O Processo Legislativo das Leis de Iniciativa Popular}

As informações sobre o processo legislativo do projeto de lei analisado neste trabalho, bem como de documentos digitalizados e os perfis biográficos dos deputados, foram extraídas do sistema de acompanhamento no site da Câmara dos Deputados, que estão disponíveis publicamente.

Ressalta-se que vários autores, ao trabalharem o tema das IPL no Brasil, focam a sua análise na construção do projeto, na coleta de assinaturas e na pressão feita pelas associações e movimentos sociais envolvidos neste processo na Câmara dos Deputados, 
porém poucos analisaram o processo legislativo em si, principalmente o papel do Poder Executivo na aprovação e formulação do conteúdo destas matérias.

Nesse artigo, tentaremos suprimir essa lacuna. Utilizando como base os estudos sobre processo decisório e funcionamento das coalizões, buscaremos perceber qual o papel das instituições no tratamento desse input popular por excelência no processo legislativo.

Além disso, pretendemos mostrar que o Poder Executivo não se mostra inerte ou alijado da construção do conteúdo e da votação das IPL. Levando em conta uma aparente ausência de participação do Executivo na aprovação de matérias oriundas da iniciativa popular, pesquisadores deixam de perceber a intersecção entre o conteúdo da Lei de Iniciativa Popular e a agenda do Poder Executivo. Tal congruência (similaridade entre a agenda governamental e o conteúdo da proposta popular) se mostra fundamental para a aprovação das políticas públicas encaminhadas ao Congresso através do instituto da iniciativa popular, já que o Executivo possui os subsídios institucionais necessários para efetivar a aprovação da matéria.

\section{Regras internas da Câmara dos Deputados e a distribuição de poderes}

As regras internas da Câmara dos Deputados, definidas no Regimento Interno desta casa legislativa, garantem aos líderes dos partidos ocupantes da Mesa Diretora e do Colégio dos Líderes um papel basilar para a condução do processo legislativo e para a ocupação das cadeiras nas Comissões (LIMONGI, 2010).

Santos (2002) fazendo uma comparação do período democrático atual e do período democrático de 1946 até o golpe militar de 1964, aponta que o período atual possui três instituições fundamentais para organizar o processo decisório, desconhecidas no período anterior: o Colégio de Líderes, limitações para a apresentação de emendas em plenário de legisladores individuais e o encaminhamento de votos pelos líderes.

Segundo o Regimento Interno da Câmara dos Deputados (RICD), o Colégio de Líderes é formado pelos Líderes da Maioria, da Minoria, dos Partidos, dos Blocos Parlamentares e do Governo, sendo que os Líderes de Partidos que participem de Bloco 
Parlamentar e o Líder do Governo terão direito à voz no Colégio de Líderes, mas não ao voto.

O RICD (BRASIL, 1989) elenca uma série de atribuições ao Colégio de Líderes, dentre eles: ser ouvido na decisão da Mesa da Câmara que fixa o número de membros efetivos das Comissões Permanentes; participar de reuniões com os presidentes das Comissões Permanentes para exame e assentamento de providências relativas à eficiência do trabalho; convocar sessão extraordinária, com duração de quatro horas, destinada exclusivamente à discussão e votação das matérias constantes da Ordem do Dia, além de poder prorrogar por uma hora a sessão solicitada; prorrogar o tempo destinado à discussão da Ordem do Dia; convocar a sessão secreta na Câmara dos Deputados, e, por último, talvez o mais importante para organização do processo legislativo, o RICD afirma que a matéria que tenha preferência solicitada pelo Colégio de Líderes será apreciada logo após as proposições em regime especial.

Santos (2002) afirma que não existia, no período democrático de 1946-64, nenhum instrumento parecido com o Colégio de Líderes, o que denota pouca influência dos líderes partidários nas votações da Câmara. Segundo o autor:

O Colégio de Líderes foi criado em 1989 como organismo auxiliar da Mesa Diretora da Câmara para assuntos relacionados ao calendário de votações da Casa. Ele tem importância decisiva nos pedidos de urgência para a votação de projetos específicos, o que significa que as proposições devem ser votadas no prazo de 45 dias. O pedido de urgência é encaminhado à Mesa pelo Colégio de Líderes, e a assinatura de cada líder é ponderada pelo tamanho da bancada sob seu comando. Em seguida, o pedido é enviado ao plenário da Câmara para ser votado, o que pode ser feito por manifestação simbólica (SANTOS, 2002, p. 243).

O segundo ponto levantado pelo autor, como importante para a organização do processo decisório na Câmara, é a proibição de emendas em plenário por legisladores individuais. De acordo com as atuais normas internas da Câmara, quando um projeto é submetido à votação em regime de urgência, os deputados não podem oferecer emendas em plenário, salvo se essas emendas contarem com a assinatura de pelo menos um décimo da Câmara ou dos líderes cujas bancadas representam esse número (SANTOS, 2009).

Lembramos, também, que além dos casos de projetos em regime de urgência, a possibilidade de emenda a projetos por parte de deputados individuais em plenário foi limitada pelo RICD ao primeiro turno de votação da matéria. Segundo o artigo 120 do 
referido Regimento, qualquer Deputado ou Comissão só poderá propor emendas durante a discussão em apreciação preliminar no turno único ou primeiro turno. Durante a discussão em segundo turno, as emendas de Plenário só poderão ser apresentadas por Comissão, se aprovada pela maioria absoluta de seus membros ou quando forem subscritas por um décimo dos membros da Casa, ou Líderes que representem este número.

Por último, segundo Santos (2002), no período pré-64, a prática de encaminhamento de voto pelos líderes era desconhecida. $\mathrm{O}$ encaminhamento de votos pela liderança está inscrita no artigo 192 do RICD, e prevê a possibilidade de cada Líder manifestar-se, após anunciada a votação de determinada matéria, para orientar sua bancada, ou indicar deputado para fazê-lo em nome da Liderança, pelo tempo não excedente a um minuto.

Para o autor, a mudança no papel das lideranças políticas do antigo período democrático (1946-64) para o atual se dá pelo fato de os partidos políticos serem mais relevantes para os parlamentares em suas negociações com o poder Executivo.

Organizados em partidos minimamente disciplinados, eles protegem-se da ação monopólica do presidente. Isso, por sua vez, garante o fluxo de projetos no plenário da Câmara e, em compensação, os legisladores recebem do Executivo benefícios de patronagem a ser distribuídos em seus redutos eleitorais. Nesse sentido, a adesão às proposições políticas do partido é um bem público para a bancada como um todo, e esse benefício somente pode ser alcançado se os parlamentares delegam aos líderes uma parte considerável de seu controle sobre a pauta legislativa com a finalidade de remover os problemas de coordenação (SANTOS, 2002, p. 244).

Nesse contexto, com base em pesquisas empíricas sobre o comportamento das lideranças nos processos decisórios, Santos (2002) defende que, a partir da Constituição de 1988, o êxito do governo passou a depender de uma coalizão estruturada de forma consistente. A presidência negocia com os partidos e não com parlamentares individuais ou facções partidárias. A ideia de alianças ad hoc, formadas para votação de matérias específicas, que dependiam de uma distribuição marginal de patronagem, foi modificada por coalizões governamentais que detêm um certo grau de disciplina, dando previsibilidade ao sistema.

Os Líderes partidários também têm uma forte influência no número e na composição das comissões. O RICD afirma que o número de membros efetivos das 
Comissões Permanentes será fixado por ato da Mesa, ouvido o Colégio de Líderes, no início dos trabalhos de cada legislatura. Além disso, após ser definida a representação numérica dos Partidos e Blocos Parlamentares nas Comissões, os Líderes possuem o dever de comunicar à Presidência, no prazo de 5 (cinco) sessões, os nomes dos membros das respectivas bancadas que as integrarão, seja como titulares ou como suplentes.

Para Santos (2002), o principal fator que é utilizado para a escolha de membros para ocupar a comissão é a especialização prévia na matéria em que a comissão trabalha. Para o autor, a maneira mais segura de se aferir o grau de especialização prévia de um parlamentar em determinada matéria é a sua experiência profissional. Somado a isso, “quando não há na bancada profissionais bem informados nos temas relacionados com a atividade da comissão, os líderes vão procurar proxies em experiências profissionais prévias" (SANTOS, 2002, p. 251). As comissões serviriam para trazer conhecimento especializado ao processo legislativo, considerando que os ocupantes das suas cadeiras teriam certo conhecimento sobre as matérias discutidas e deliberadas.

Nesse contexto de alta rotatividade dos deputados nas comissões, o Poder Executivo, através dos líderes de partidos ou da coalizão que apoia o governo, possui um alto poder sobre as comissões, podendo interferir na substituição dos seus membros, colocando um número estratégico de membros aliados, em caso de ameaça de derrota em uma votação importante para sua agenda (PEREIRA; MUELLER, 2000).

Para estes autores, os Líderes possuem a prerrogativa de

nomear, assim como substituir, a qualquer momento, os membros das comissões (art.10). Não há restrições quanto ao tempo de permanência dos deputados nas comissões. Aparentemente, existe uma auto seleção por parte dos deputados, porém, há evidências de que líderes dos partidos interferem significativamente no processo de nomeação dos integrantes da comissão. (PEREIRA; MUELLER, 2000, p. 48-49)

Outro ponto que interfere diretamente no andamento das propostas nas comissões é o pedido de urgência. Ele pode ser requerido, conforme Art. 154 do RICD, tanto por um terço dos membros da Câmara, ou líderes que representem esse número, como por dois terços dos membros de uma Comissão ou da Mesa Diretora, limitando assim ações individuais de deputados que não estão organizados ou que não se adequem à racionalidade da centralização do processo (SANTOS, 2006). 
Pereira e Mueller (2000) defendem a ideia de que o poder das comissões no Congresso brasileiro tem uma base institucional muito fraca. Apesar do poder terminativo, que possibilita à comissão aprovar uma proposta diretamente, sem que esta seja discutida no plenário, o pedido de urgência, na prática, impossibilita a utilização do poder terminativo por parte da Comissão.

Utilizando do poder de urgência, o Executivo ou o Colégio de Líderes força a saída da proposta em debate na Comissão e a transfere para o Plenário da casa legislativa. Prova desta ideia, segundo os autores citados acima, é de que das 805 propostas aprovadas entre 1985 e 1998, as comissões fizeram uso do seu poder terminativo em apenas 106 $(13,16 \%)$, e somente 71 propostas $(8,81 \%)$ foram aprovadas nas comissões sem nenhuma emenda do Plenário (PEREIRA; MUELLER, 2000).

A mesma ideia é defendia por Santos (2006). Para o autor são os líderes que, na prática, controlam o fluxo de trabalhos no Legislativo. Através deles, as matérias são direcionadas ao plenário, que passa a ser o principal local de decisão, rebaixando as comissões a um lócus de poder secundário e descentralizado. Para o autor,

As comissões e o plenário são esvaziados como instâncias decisórias na medida em que as discursões substantivas são deliberadas no Colégio de Líderes. A participação dos parlamentares é, então, restrita à fase final do processo, quando a lei é submetida à votação. A centralização decisória no Colégio de Líderes favorece o Executivo ao diminuir incertezas próprias de um processo de negociação descentralizado" (SANTOS, 2006, p. 232).

Porém, esta visão sobre o Colégio de Líderes não é unânime. O RICD prevê, em seu artigo 20, parágrafo $2^{\circ}$, que sempre que for possível, as “deliberações do Colégio de Líderes serão tomadas mediante consenso entre seus integrantes; quando isto não for possível, prevalecerá o critério da maioria absoluta, ponderados os votos dos Líderes em função da expressão numérica de cada bancada" (BRASIL, 1989). Apesar do importante papel do Colégio de Líderes estipulado pela norma interna da Câmara dos Deputados, além do que foi apontado pela literatura anteriormente, Cintra e Lacombe (2015) apontam que neste Colegiado, historicamente, não se segue as instruções regimentais.

Um exemplo disso, segundo os autores, foi o que ocorreu na votação da Lei Complementar $n^{\circ} 135$, de 2010, conhecida como Lei da Ficha Limpa. Sem acordo entre os líderes para a aprovação da matéria, o então presidente da Câmara Michel Temer (PMDB-SP), decidiu colocar o projeto em pauta, com a deliberação de que, caso algum 
Líder não concordasse com a votação do projeto, poderia apresentar requerimento de retirada de pauta em plenário. Apesar de apresentados os requerimentos pelos líderes de alguns partidos, estes foram rejeitados em plenário, restando a aprovação da matéria.

Analisando esta prerrogativa, Rocha e Barbosa (2008) demonstram que a utilização do pedido de urgência é muito mais frequente em projetos de leis iniciados pelo poder Executivo, e que a maioria dos pedidos é feita pelo próprio Congresso. Assim, observam os autores, os próprios parlamentares criam obstáculos para o trabalho nas comissões, impedindo-as de analisar de forma mais aprofundada os projetos de lei.

O sistema de comissões brasileiro é gerido por regras do processo decisório que acabam centralizando e reservando poderes nas mãos das lideranças partidárias, entre esses poderes, os de designar membros para ocupar as comissões. Para Rocha e Barbosa (2008), não é possível estabelecer uma lógica inequívoca sobre o funcionamento das comissões, porém, pode-se identificar fatores que contribuem para sua participação ativa no processo decisório, e fatores que limitam o seu adequado funcionamento:

Entre as primeiras, assinalam-se: os poderes de iniciativa legislativa e emenda, a possibilidade de apreciar conclusivamente matérias, de peticionar a autoridades públicas e os mecanismos de interlocução com a sociedade. Já entre as segundas, destacam-se: o tamanho das comissões (entre 25 e 51 participantes), a ausência de regras que incentivem a permanência do legislador na comissão e que impeçam a alta rotatividade dos mesmos, e a prerrogativa do Presidente e das lideranças partidárias de pedir urgência na tramitação das leis (ROCHA; BARBOSA, 2008, p. 101).

Porém, Freitas (2016) possui outra visão sobre o tema. Segundo a autora, o argumento de que as Comissões são fracas e com pouca importância advém de uma comparação com o sistema de comissões norte-americano. Neste país, para o projeto ser votado em plenário, necessariamente, deve haver uma deliberação da comissão que o analisa, não havendo outro meio dele ser retirado desta.

A autora mostra que é equivocado ignorar a importância das comissões por, basicamente, dois motivos. O primeiro diz respeito ao pedido de urgência: de todos os Projetos de Lei e Projetos de Lei Complementar que foram aprovados no Congresso de 1988 a 2010, em regime de urgência, 45\% deles foram votados em plenário com parecer do relator do projeto na Comissão. Ou seja, houve deliberação dentro da comissão, apesar do pedido de urgência. 
Além disso, 22\% dos projetos que foram aprovados no período com pedido de urgência, já haviam passado por todo o rito interno do processo ordinário, antes mesmo da urgência ser solicitada. O requerimento de urgência, nesses casos, não possuiu o condão de evitar oposições de legisladores. Assim, "a urgência não constitui aqui um poder para oprimir ou inibir a ação dos parlamentares, antes disso, é um poder de agenda, utilizado para pôr em pauta um projeto" (FREITAS, 2016, p. 78).

Para a autora, o pedido de urgência não é utilizado como arma de evitar uma comissão oposicionista ou minar o poder de congressistas oportunistas; nesse contexto, o pedido de urgência se encaixa como um instrumento que é utilizado para levar o projeto à ordem do dia - geralmente abarrotada de projetos. Caso a urgência não seja solicitada, o projeto deve aguardar em uma fila para votação em plenário, onde as Medidas Provisórias e os Projetos de Lei com urgência constitucional possuem prioridades (FREITAS, 2016).

\section{Lei 8.930/94 - A modificação na lei de crimes hediondos}

A Lei $n^{\circ} 8.930$ (BRASIL, 1994), que alterou a lei de crimes hediondos, ficou conhecida pelo nome "Projeto de Iniciativa Popular Glória Perez", em homenagem à autora de telenovelas da Rede Globo, que foi a principal patrocinadora do projeto. Glória Perez iniciou a campanha de coleta de assinaturas no ano de 1992, após a morte de sua filha Daniella Perez, brutalmente assassinada pelo ator com quem contracenava em uma novela de grande público à época.

O projeto de lei 4.146 de 1993, pretendia alterar redação do Artigo $1^{\circ}$ da Lei ${ }^{\circ}$ 8.072/1990, incluindo o crime de homicídio qualificado no rol dos crimes considerados hediondos. A redação final do projeto acabou por incluir os seguintes crimes no referido rol: homicídio, quando praticado em atividade típica de grupo de extermínio, ainda que cometido por um só agente, e homicídio qualificado; latrocínio; extorsão qualificada pela morte; extorsão mediante sequestro e na forma qualificada; epidemia com resultado morte; e genocídio.

Porém, durante a conferência acerca do cumprimento dos procedimentos legais, verificou-se que o projeto possuía vícios formais relacionados à coleta das assinaturas, o que impediu que este fosse apresentado como projeto de lei de iniciativa popular. Com 
esta impossibilidade, o projeto foi “adotado" pela Presidência da República e encaminhado para Câmara dos Deputados (MELCHIORI, 2011).

O referido projeto de lei, primeiramente, foi encaminhado pelo Poder Executivo ante a apresentação pelo então Ministro da Justiça, Mauricio Corrêa, da proposta de Indicação Legislativa encaminhada pelo Conselho Estadual da Criança e do Adolescente do Estado do Rio de Janeiro no dia 25 de agosto de 1993, visando incluir os esquadrões da morte no rol de crimes hediondos.

Com essa proposta, os autores fazem referência direta à Chacina da Candelária, onde, no dia 23 de julho de 1993, oito jovens, incluindo seis crianças e adolescentes, foram assassinados, próximo à igreja da Candelária no Rio de Janeiro, por um grupo de extermínio formado, majoritariamente, por policiais militares.

A redação original do projeto, vinda através do Poder Executivo, previa a modificação do Artigo $1^{\text {o }}$ da lei de Crimes Hediondos (BRASIL, 1990), a fim de incluir nesse rol o crime de homicídio, quando praticado em atividade típica de grupo de extermínio, ainda que cometido por um só agente.

A essa proposição, foi anexada pelo Presidente da Câmara dos Deputados, Deputado Inocêncio de Oliveira (PFL-PE), através do Ofício SGM no 940 de 14 de outubro de 1993, o projeto oriundo da participação popular, subscrito por mais de um milhão e trezentas mil assinaturas.

Neste oficio, o Presidente da Câmara relata que, em audiência realizada no dia 5 de outubro, recebeu das mãos de comissão integrada por advogados, artistas e mães cujas famílias se tornaram vítimas da violência, um projeto de lei que visava alterar o artigo primeiro da lei de crimes hediondos, a fim de que nele constasse e fosse inserido como crime hediondo, o "homicídio qualificado".

É considerado qualificado, de acordo com o Código Penal Brasileiro - Art. 121, § $2^{\circ}$ - todo homicídio praticado:

I - mediante paga ou promessa de recompensa, ou por outro motivo torpe; II por motivo fútil; III - com emprego de veneno, fogo, explosivo, asfixia, tortura ou outro meio insidioso ou cruel, ou de que possa resultar perigo comum; IV à traição, de emboscada, ou mediante dissimulação ou outro recurso que dificulte ou torne impossível a defesa do ofendido; V- para assegurar a 
execução, a ocultação, a impunidade ou vantagem de outro crime (BRASIL, 1940).

O Projeto de lei 4.146 de 1993, que originou a supracitada modificação legislativa, teve uma rápida tramitação na câmara dos deputados. Desde sua apresentação no Plenário daquela Casa Legislativa até a sua aprovação final, passaram-se apenas 11 meses.

Após o recebimento do projeto, a Presidência da Câmara encaminhou a proposta legislativa, acompanhada pelas assinaturas que a subsidiavam, para a Comissão de Constituição e Justiça da Câmara dos Deputados.

Ao ser enviado à Comissão de Constituição e Justiça e Redação, coube a relatoria do projeto ao então deputado José Luiz Clerot (PMDB-PB). O Relator considerou em seu voto, que a proposição proveniente do Poder Executivo, apresentava uma redação insuficiente, já que considerava como hediondo o homicídio quando cometido em atividade típica de grupo de extermínio, ainda que praticado por um só agente. No seu voto, o relator afirmou ser impossível um grupo ser formado por uma só pessoa, considerando a proposta advinda da manifestação popular e encaminhada pelo Ofício SGM n ${ }^{\circ} 940$ de 14 de outubro de 1993, bastante superior.

Sendo assim, o referido Relator do Projeto na Comissão de Constituição e Justiça, no dia 15 de março, optou por propor uma emenda ao projeto enviado pelo Executivo, estabelecendo a alteração da lei de crimes hediondos no seguinte sentido: "homicídio qualificado, consumado ou tentado, quando praticado em atividades típicas de grupo de extermínio, ainda que cometido por um só agente" (PORTAL DA CÂMARA DOS DEPUTADOS).

Porém, ao apresentar o voto no plenário da Comissão, o mesmo foi criticado pelos deputados José Abrão (PSDB-SP), Luiz Máximo (PSDB-SP), Ibrahim Abi-Ackel (PDSMG) e Edmundo Galdino (PSDB-TO), que reformularam o parecer do Relator e aprovaram na Comissão de Constituição e Justiça, em 23 de março de 1994, o Projeto de lei do Poder Executivo n 4.146 de 1993, acrescentando, a feito de emenda, a expressão "e homicídio qualificado, consumado ou tentado", in fine.

Com isso, a Comissão de Constituição e Justiça da Câmara dos Deputados fundiu, integralmente, as duas proposições de alteração da lei de crimes hediondos. Ou seja, tanto 
o projeto de origem do Poder Executivo quanto o de origem da iniciativa popular, anexado pelo Presidente da Câmara, foram contemplados no texto final da Comissão.

A CCJ da Câmara dos Deputados contava com 45 membros, ${ }^{1}$ divididos em 15 partidos, como mostra o gráfico:

Gráfico 1: Composição partidária da Comissão de Constituição e Justiça no caso da "Lei de Crimes Hediondos"

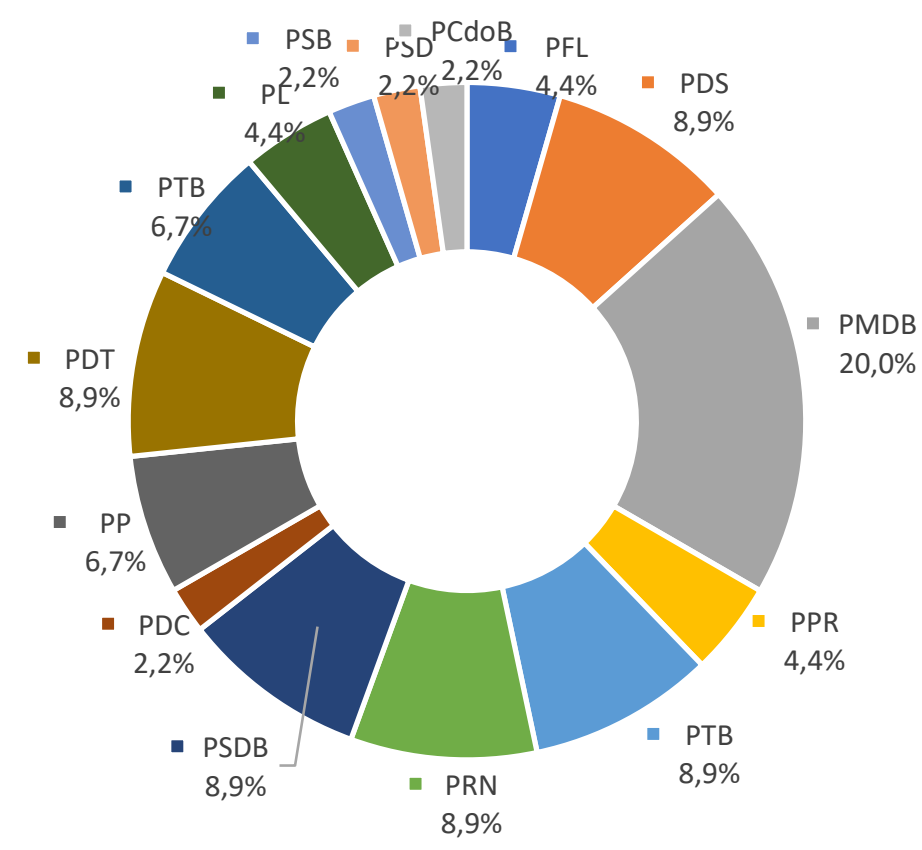

Fonte: Elaboração própria com base nos dados disponíveis no banco de dados da Câmara dos Deputados (Portal da Câmara dos Deputados)

\footnotetext{
${ }^{1}$ José Thomaz Nono - PFL/AL (Presidente da Comissão); Ibrahin Abi - PDS/MG; Jose Dutra PMDB/AM; Vilmar Rocha - PFL/GO; Carlos Kayath - PTB/PA; Joao Natal - PMDB/GO; José Clerot PMDB/PA; Maurici Mariano - PRN/SP; Mendes Ribeiro - PMDB/RS; Fernando Diniz - PMDB/MG; Gilvan Borges - PMDB/AP; Joao Henrique - PMDB/PI (vice-líder do seu partido na CD); Délio Braz PMDB/GO; Mauricio Calixto - PTB/RO; Antônio Geraldo - PRN/PE; Gerson Peres - PPR/PA (líder do PPR de 1993-1994); José Burnett - PRN/MA; José Eymael - PPR/SP; Osvaldo Melo - PDS/PA; Prisco Viana - PMDB/BA; Vasco Furlan - PDS/SC: Edmundo Galdino - PSDB/TO; José Abrão - PSDB/SP; Luiz Máximo - PSDB/SP; Moroni Torgan - PDC/CE; Paulo Silva - PSDB/PI; Benedito Domingos PP/DF (primeiro vice-líder do seu partido, em 1994); Carlos Scapelini - PP/PR; Edison Fidelis - PTB/RO; Luiz Carlos Hauly - PP/PR (vice-líder do seu partido em 1994, e vice-líder do Governo, em 1994); Benedito de Figueiredo - PDT/SE (vice-líder do PDT, de 1993-1994); Beth Azize - PDT/AM (primeiro vice-líder do PDT, 1994); Neiva Moreira - PDT/MA; Wilson Muller - PDT/RS (vice-líder do seu partido); Edésio Passos - PT/PR; Helvécio Castello - PL/ES; José Dirceu - PT/SP; Pedro Tonelli - PT/PR; Ervin Bonkoski - PTB/PR; Oscar Travassos - PDS/MT; Ricardo Corrêa - PL/MT; Irani Barbosa - PSD/MG; Roberto Franca - PSB/PE; Sérgio Miranda - PCdoB/MG (vice-líder do PCdoB, em 1994); Euclydes Mello PRN/SP.
} 
Segundo Figueiredo, Rosa e Rodrigues (2012), a coalizão governamental, na data da tramitação do projeto em análise, contava com os partidos: PFL, PMDB, PSDB e PP. Juntos, esses partidos possuíam, além da presidência da Comissão e a Relatoria do projeto, quase $40 \%$ das cadeiras da CCJ, o que lhes dava margem para, em negociação com partidos de centro, aprovar as matérias de interesse do governo na Comissão.

Para fins de comparação, os partidos que não faziam parte da coalizão de Itamar Franco seriam o PT e o PDT. Mesmo se contabilizássemos o PCdoB como integrante de um polo oposicionista dentro da CCJ, esses partidos somariam 17,76\% das cadeiras. Porém, na votação do projeto, e com base nos documentos sobre sua tramitação na CCJ da Câmara (PORTAL DA CÂMARA DOS DEPUTADOS), esses três partidos não tentaram obstruí-lo, nem modificar o seu conteúdo.

Como dito anteriormente, o PSDB teve um papel importante na discussão do conteúdo do relatório e da emenda substitutiva proposta pela Comissão. Foi através da atuação de 3 dos seus 4 deputados, que o parecer do relator foi reformulado, e o acordo sobre a redação final do projeto foi feita.

O projeto foi discutido em turno único no plenário, no dia 24 de março de 1994. Após um longo debate, o presidente da Câmara dos Deputados, deputado Inocêncio Oliveira (PFL-PE), com base em solicitações feitas pelos Líderes, abriu um prazo de um dia para a propositura de emendas ao projeto, e o enviou para a Comissão de Constituição e Justiça.

O projeto foi alvo de duas emendas. A primeira, tratou-se de uma Emenda Supressiva impetrada pelo deputado Nelson Trad (Líder do PTB), que visava retirar do texto aprovado pela CCJR, a caracterização dos crimes de homicídio qualificado (tanto na sua forma tentada como na consumada) como hediondos, restringindo-o assim às modificações feitas na Comissão.

Na justificativa da Emenda Supressiva, o referido deputado afirma que o cerne do problema da criminalidade é de ordem social e não punitivista. Para isso, ele defendeu a distribuição de renda e oportunidade para que a população mais carente, que sofre as mazelas do sistema criminal, possa escapar de um ciclo de criminalidade. 
Caso a emenda supressiva do deputado viesse a ser acolhida, na prática, significaria a não aceitação do projeto oriundo da iniciativa popular, já que este versava justamente sobre a majoração da punição e a previsão destes delitos como hediondos.

A segunda Emenda consistia em adicionar casos ao rol de crimes hediondos. A proposta foi apresentada pela deputada Regina Gordilho (PRONA-RJ), visando acrescentar ao projeto os crimes praticados por ministros de Estado, governadores, senadores, deputados, prefeitos e vereadores que cometessem as seguintes infrações: desvio de verbas, omissões quanto a roubos em repartições, permissões de espancamento e violência em favelas, e que contribuíssem para o extermínio da população indígena.

Em sua justificativa, a deputada pleiteia o acréscimo desses crimes para que as autoridades constituídas possam ser responsabilizadas, tanto civil como criminalmente pelos atos praticados em suas gestões, combatendo o sentimento de impunidade que paira sobre elas.

Remetido novamente para a Comissão de Constituição e Justiça e Redação, a fim de prosseguir com as análises e se manifestar sobre as proposições, as duas foram rejeitadas por unanimidade na votação da Comissão.

De acordo com o voto do relator José Luiz Clerot (PMDB/PB) e, posteriormente, sancionado unanimemente pela Comissão, a primeira emenda foi rejeitada por

suprimir do projeto aspecto que dele ainda não faz parte, ou seja, retirar do rol
dos crimes hediondos o homicídio qualificado que, até agora, é objeto de
emenda adotada por esta Comissão a ser apreciada pelo Plenário da Casa.
Aliás, diga-se, por oportuno, que o caminho a ser seguido pelos que querem
evitar a inclusão do homicídio qualificado no rol dos crimes hediondos, será
votar em Plenário pela rejeição da emenda já adotada por esta Comissão
(PORTAL DA CÂMARA DOS DEPUTADOS).

Para esclarecer o caso, lembramos que o projeto em votação na Câmara dos Deputados foi originário do Poder Executivo, sendo que o projeto de lei originário da participação popular (que previa o enquadramento do homicídio qualificado no rol de crimes hediondos) foi apensado ao do Executivo, tendo sido seus conteúdos fundidos pela emenda substitutiva aprovada na CCJ.

Já a segunda emenda, apresentada pela deputada Regina Gordilho do PRONA/RJ, foi rejeitada com a justificativa de não possuir a técnica legislativa correta para a inserção das condutas proposta pela deputada na lei de crimes hediondos. Segundo o voto do 
Relator, "adotar a sugestão da deputada abre caminho para inserir na lei de crimes hediondos todas as figuras típicas descritas pela lei penal" (PORTAL DA CÂMARA DOS DEPUTADOS).Em seu retorno ao Plenário da Câmara dos Deputados, as emendas propostas anteriormente foram votadas pelo processo simbólico, no qual o presidente anuncia a votação da matéria e convida que os deputados a favor permaneçam sentados, dando o resultado da votação em seguida.

Os presentes votantes acolheram a emenda feita na CCJR, incluindo os crimes de homicídio qualificado no rol de crimes hediondos. Sendo assim, restou prejudicada a primeira emenda feita no plenário da Câmara pelo deputado Nelson Trad (PTB).

Posta em votação a segunda emenda, proposta pela Deputada Regina Gordilho, os Líderes do PMDB, Germano Rigoto (PPR), Arnaldo Farias de Sá (PT) e José Fortunatti (PT), indicaram que seus partidos eram contrários à aprovação da emenda. Ao final, ela foi rejeitada.

Quadro 1 - Síntese de tramitação da "Lei de Crimes Hediondos"

\begin{tabular}{|l|l|}
\hline Partido e órgão dos “adotantes" & Executivo (PMDB) \\
\hline Parecer em Comissões & CCJR \\
\hline Relator & PMDB \\
\hline Parecer do relator & Favorável com Emendas \\
\hline Emendas de Comissão & PSDB e PDS \\
\hline Resultado na Comissão & Aprovado com Emenda \\
\hline Emendas de Plenário & PTB (supressiva) - Rejeitada \\
\hline Obstrução da Oposição & PRONA (aditiva) - Rejeitada \\
\hline Resultado da Tramitação & Não \\
\hline Tipo de Votação & Aprovado Projeto com Emenda da CCJR \\
\hline Requerimento de Urgência & Simbólica \\
\hline Tempo de Tramitação & Não \\
\hline
\end{tabular}

Fonte: Elaboração do autor com base nos dados disponibilizados no Portal da Câmara dos Deputados

O quadro 1 sintetiza os principais pontos encontrados durante a análise do processo legislativo, do primeiro projeto de iniciativa popular aprovado no Brasil. Podemos visualizar o papel do Poder Executivo e a sua coligação, como importantes para 
a aprovação da matéria, mantendo a relatoria na Comissão de Constituição e Justiça da Câmara, bem como rejeitando as propostas de emenda apresentadas em plenário.

Por fim, é necessário dar ênfase ao tempo de duração da tramitação deste projeto no Congresso. O projeto, desde a sua proposta até o a votação e aprovação final, ficou tramitando na Câmara dos Deputados por apenas onze meses, o que denota um interesse da Mesa Diretora e dos Líderes partidários em dar uma resposta célere à demanda da população. Uma pressão externa, vinda de um contexto de chacinas e crimes de grande repercussão midiática, juntamente com uma coalizão coordenada e sem grandes empecilhos da oposição, fizeram com que o projeto tivesse uma tramitação razoavelmente rápida.

\section{Considerações Finais}

A votação da redação final do projeto, que seguiu o processo simbólico, teve como resultado a aprovação integral do conteúdo decidido dentro da CCJR. A participação de partidos da oposição, como o PT, não só foi no sentido de não obstruir, mas no sentido de apoiar o texto original definido na Comissão. Da leitura em plenário da matéria (07 de outubro de 1993) até a sua votação final em setembro de 1994, o trâmite total do projeto durou onze meses.

A análise deste caso específico demonstra que, para a aprovação da Lei 8.930/94, o lócus principal de decisão sobre o conteúdo aprovado foi a Comissão de Constituição e Justiça da Câmara. Foi lá que seu conteúdo foi estabelecido, e a atuação dos partidos em plenário demonstra sintonia com a unanimidade presente na votação dos pareceres emitidos pela Comissão e seus partidos integrantes.

Após a aprovação do trabalho do relator pela Comissão, este passou a servir de base para todas as decisões em plenário. Depois de votado na Comissão de Constituição e Justiça, o Plenário da Câmara nada acrescentou ao conteúdo do projeto. Foi nessa comissão que a redação foi discutida e (re)formulada.

O papel do Poder Executivo também não pode ser deixado de lado na análise desse projeto. Ao ser anexado aos projetos de lei do Poder Executivo, ou ter um patrocínio direto, o projeto de lei de iniciativa popular já entrava com um tratamento diferenciado, 
dispensando a análise em algumas comissões e agilizando o seu trâmite. O conteúdo final da lei votada foi o resultado da união do projeto original enviado pelo Governo e da propositura popular, resultando em uma junção de preferências institucionais e populares para o conteúdo da lei.

Por fim, podemos perceber que as únicas duas emendas propostas em plenário, vieram de membros de partidos que não integravam a coalização governamental. Isso nos leva a pensar que a lógica apontada pelos autores citados anteriormente, se faz presente quando o assunto analisado é as leis de iniciativa popular.

Podemos deduzir, neste caso estudado, que na aprovação da primeira lei de iniciativa popular brasileira, houve, desde o recebimento da proposta no Congresso Nacional, um arranjo envolvendo tanto forças externas ao Congresso quanto fatores institucionais. Esses fatores foram coordenados pela Coalizão governamental, e o conteúdo final da lei foi o resultado desta dinâmica.

\section{Referências}

ALTMAN, David. Plebiscitos, referendos e iniciativas populares en América Latina:i mecanismos de control político o políticamente controlados? Perfiles latinoamericanos, México, v. 18, n. 35, p. 9-34, 2010. Disponível em: http://www.scielo.org.mx/ scielo.php?pid=S0188-76532010000100001\&script=sci_arttext. Acesso em: 20/01/2019.

AVRITZER, Leonardo. Reforma política e participação no Brasil. In: AVRITZER, Leonardo; ANASTASIA, Fátima (Orgs.). Reforma política no Brasil. Belo Horizonte: Ed. UMFG, 2006, p. 35-44.

BENEVIDES, Maria Victoria de Mesquita. A cidadania ativa. São Paulo: Ática, 1991.

BRASIL. Decreto-Lei no 2.848 de 07 de dezembro de 1940. Código Penal. Brasília: Presidência da República, [1940]. Alterado por leis posteriores. Disponível em: http://www.planalto.gov.br/ccivil_03/decreto-lei/del2848compilado.htm. Acesso em: 19 dez. 2019.

BRASIL. Lei Constitucional no 9 de 1945.Dá nova redação a artigos da Constituição. Brasília: Câmara dos Deputados, [1945]. Disponível em: https://www2.camara.leg.br/ legin/fed/leicon/1940-1949/leiconstitucional-9-28-fevereiro-1945-365005-publicacao original-1-pe.html. Acesso em: 19 dez. 2019.

BRASIL. Câmara dos Deputados. Regimento Interno: Resolução n.17, de 1989. Aprova o Regimento Interno da Câmara dos Deputados. Brasília: Câmara dos Deputados [1989]. Disponível em: https://www2.camara.leg.br/atividade-legislativa/legislacao/regimento- 
interno-da-camara-dos-deputados/arquivos-1/ricd\%20atualizado\%20ate\%20rcd\%20\%2 012-2019.pdf. Acesso em: 16/12/2019.

BRASIL. Lei $\quad \mathbf{n}^{\mathbf{0}} \mathbf{8 . 0 7 2}$ de 25 de julho 1990. Dispõe sobre os crimes hediondos, nos termos do art. $5^{\circ}$, inciso XLIII, da Constituição Federal, e determina outras providências. Brasília: Presidência da República, [1990]. Disponível em: http://www.planalto.gov.br/ccivil_03/leis/18072.htm. Acesso em: 19/12/2019.

BRASIL. Lei $\mathbf{n}^{\mathbf{0}} \mathbf{8 . 9 3 0}$ de 06 de setembro 1994. Dá nova redação ao art. $1^{\text {o }}$ da Lei n⿳⺈ 8.072 , de 25 de julho de 1990, que dispõe sobre os crimes hediondos, nos termos do art. 5o , inciso XLIII, da Constituição Federal, e determina outras providências. Brasília: Presidência da República, [1994]. Disponível em: http://www.planalto.gov.br/ccivil_03/leis/L8930.htm. Acesso em: 19/12/2019.

CÂMARA DOS DEPUTADOS. Portal. Disponível em: https://www.camara.leg.br/ proposicoesWeb/prop_mostrarintegra;jsessionid=3DBB4529B346708C7288B7898F49 1F75.proposicoesWebExterno2?codteor=1138635\&filename=Dossie+-PL+4146/1993. Acesso em: 19/12/2019.

CINTRA, A. O.; LACOMBE, M. B. A câmara dos deputados na nova república: a visão da ciência política. In: AVELAR, L.; CINTRA, A. O. (Orgs). Sistema político brasileiro: uma introdução. 3. ed. Rio de Janeiro: Fundação Konrad Adenauer-Stiftung; São Paulo: Ed. Unesp, 2015, p. 143-182.

FIGUEIREDO, Argelina C.; ROSA, Gabriela R. da Guia; RODRIGUES, Leandro de P. Coalizões governamentais na democracia brasileira. Primeiros estudos, São Paulo, n. 3, p. 159-196, 2012.

FLEURY, Sonia. Iniciativa popular. In: AVRITZER; Leonardo; ANASTASIA, Fátima (Orgs.). Reforma Política no Brasil. Belo Horizonte: Ed. UFMG, 2006, p. 94-102.

FREITAS, Andréa. O presidencialismo da coalizão. Rio de Janeiro: Fundação Konrad Adenauer, 2016.

LIMONGI, Fernando. Estudos legislativos. In: MARTINS, C. B.; LESSA, R. (Orgs.) Horizontes das ciências sociais no Brasil: ciência política. São Paulo: Anpocs, 2010, p. 163-190.

MELCHIORI, Cíntia Ebner. Participação e representação política: a iniciativa popular de lei e o caso do movimento de combate à corrupção eleitoral. 2011. Dissertação (Mestrado em Gestão e Políticas Públicas) - Escola de Administração de Empresas da FGV. Disponível em: https://bibliotecadigital.fgv.br/dspace/bitstream/handle/10438/8664/DIS SERT_CINTIA\%20EBNER\%20MELCHIOR.pdf?sequence=1\&isAllowed=y. Acesso em 10 de janeiro de 2019.

PEREIRA, Carlos; MUELLER, Bernardo. Uma teoria da preponderância do poder executivo: o sistema de comissões no legislativo brasileiro. Revista Brasileira de Ciências Sociais, São Paulo, v. 15, n. 43, p. 45-67, 2000. Disponível em: 
http://www.scielo.br/scielo.php?script=sci_abstract\&pid=S0102-69092000000200004\& $\operatorname{lng}=\mathrm{en} \& n \mathrm{~nm}=$ iso\&tlng=pt. Acesso em: 21/12/2019.

ROCHA, Marta M. da; BARBOSA, Cássio Felipe. Regras, incentivos e comportamento: as comissões parlamentares nos países do Cone Sul. Revista de Sociologia e Política, Curitiba, v. 16, p. 93-104, 2008. Disponível em: http://www.scielo.br/scielo.php? pid=S0104-44782008000300007\&script=sci_abstract\&tlng=pt. Acesso em: 21/12/2019.

SANTOS, Fabiano. Partidos e comissões no presidencialismo de coalizão. Dados, Rio de Janeiro, v. 45, n. 2, p. 237-264, 2002. Disponível em: http://www.scielo.br/scielo.php? script=sci_arttext\&pid=S0011-52582002000200003. Acesso em: 19/12/2019.

SANTOS, Fabiano. Governos de coalizão no sistema presidencial: o caso do Brasil sob a égide da Constituição de 1988. In: AVRITZER, Leonardo; ANASTASIA, Fátima (Orgs.). Reforma política no Brasil. Belo Horizonte: Ed. UMFG, 2006, p. 223-236.

SANTOS, Luiz Claudio Alves dos. A participação popular na iniciativa das leis no contexto da democracia representativa e da participação política no Brasil. 2009. Dissertação (Mestrado em Ciência Política) - Instituto de Pesquisas Universitárias do Rio de Janeiro e Centro de Formação, Treinamento e Aperfeiçoamento da Câmara dos Deputados, Rio de Janeiro, 2009.

WELP, Yanina. La participación ciudadana en la encrucijada. Los mecanismos de democracia directa en Ecuador, Perú y Argentina. Íconos, Quito, n. 31, p. 117-130, 2008. Disponível em: http://www.redalyc.org/html/509/50903109/. Acesso em: 10/09/2017.

Recebido em: 19/09/2019.

Aceito em: 10/11/2019. 